\title{
Anti-CD26 Monoclonal Antibody YS110
}

National Cancer Institute

\section{Source}

National Cancer Institute. Anti-CD26 Monoclonal Antibody YS110. NCI Thesaurus. Code C150677.

A humanized, immunog lobulin G1 (IgG1) monoclonal antibody directed against the extracellular domain of dipeptidyl peptidase 4 (CD26; DPP4; DPP IV), with potential antineoplastic activity. Upon administration of anti-CD26 monoclonal antibody YS110, this antibody targets and binds to CD26 expressed on tumor cells. This inhibits CD26 activity and causes internalization of CD26-YS110. This leads to cell cycle arrest, lysis and inhibition of growth in CD26-positive tumor cells. YS110 also induces antibody-dependent cellular cytotoxicity (ADCC) and complement-dependent cytotoxicity (CDC) ag ainst CD26expressing tumor cells. CD26, a 110-kDa, type II transmembrane glycoprotein, is overexpressed in a variety of cancer cell types while absent in normal, healthy cells and plays a key role in tumor cell growth, migration, invasion and survival. It also plays a major role in the regulation of $\mathrm{T}$-cell activity. 